\title{
Role of Intolerance of Uncertainty (IU) in the etiology and treatment of emotional disorder: A mini review
}

\author{
Tahere Zahrayi ${ }^{1}$, Fayegh Youse ${ }^{2}$, Omid Saed $^{3}$ \\ 1-MS student of Clinical Psychology, Department of Clinical Psychology, Faculty of Medicine, Zanjan University \\ of Medical Sciences, Zanjan, Iran. ORCID: 0000-0003-2045-5806 \\ 2-Associate Professor, Department of Psychiatry, Faculty of Medicine, Kurdistan University of Medical Sciences, \\ Kurdistan, Sanandaj, Iran. ORCID: 0000-0001-5503-3326 \\ 3-Assistant Professor, Department of Clinical Psychology, Faculty of Medicine, Zanjan University of Medical \\ Sciences, Zanjan, Iran (Corresponding Author). ORCID: 0000-0002-6070-6203 E-mail: o.saed@ zu ms.ac.ir.
}

Received: $12 / 10 / 2018$

Accepted: 05/02/2019

\begin{abstract}
Intolerance of uncertainty (IU) is generally known as emotional, cognitive, and behavioral reactions to ambiguity situations. Several studies have considered the intolerance of uncertainty as a common factor across all of emotional disorders. The intolerance of uncertainty has two important dimensions: prospective and inhibitory. Each dimensions is also involved in a specific disorder. Due to important role of IU at development and maintenance of emotional disorders, clinicians sought to treat it. Finally, changes in IU can be contributory to recovery of various emotional disorder symptoms in transdiagnostic treatment. In this study, we have tried to address the importance of intolerance to uncertainty, investigate its place in the development and maintenance of emotional disorders and the implications for the treatment of this structure for professionals.
\end{abstract}

Keywords: Intolerance of uncertainty, Emotional disorders, Treatment of emotional disorders, Mini review

How to cite this article : Zahrayi T, Yousefi F, Saed O. Role of Intolerance of Uncertainty (IU) in the etiology and treatment of emotional disorder: A mini review. Shenakht Journal of Psychology and Psychiatry. 2019; 6 (1): 138-151 .URL :http://shenakht.muk.ac.ir/article-1-645fa.pdf

Copyright (c) 2018 the Author (s). Published by Kurdistan University of Medical Sciences. This is an open access article distributed under the terms of the Creative Commons Attribution-Non Commercial License 4.0 (CCBY-NC), where it is permissible to download, share, remix, transform, and buildup the work provided it is properly cited. The work cannot be used commercially without permission from the journal. 


\title{
نقش تحمّلنإذيرى عدم قطعيّت در سببشناسى و درمان اختلالهاى هيجانى: مقالهُ مرورى كوتاه
}

\author{
طاهر هز هرائى '، فايق يوسفى ‘، اميد ساعد"

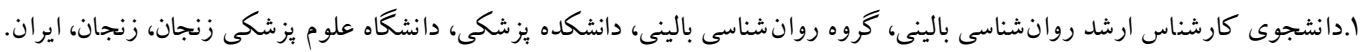

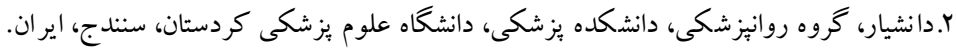

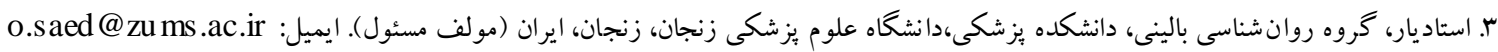

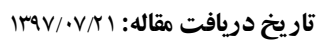

تحمّل نايذيرى عدم قطعيّت معمولاً به عنوان واكنش هاى هيجانى، شناختى و رفتارى منفى به موقعيّتهاى مبهم شناخته مىشود. مطالعات

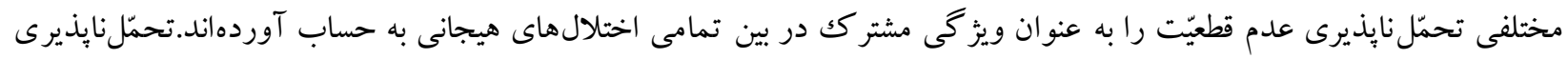

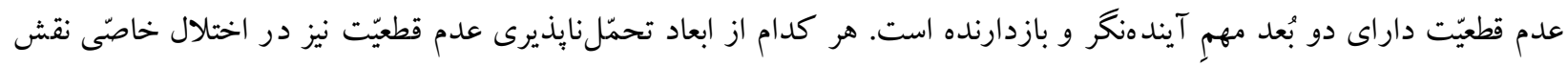

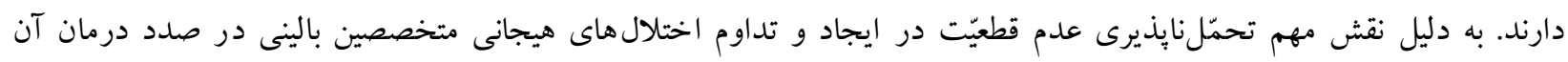

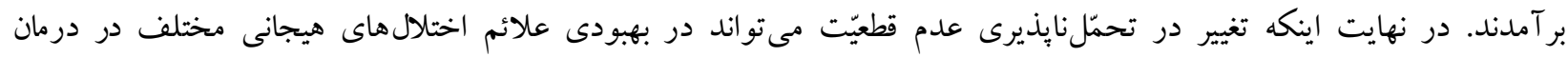

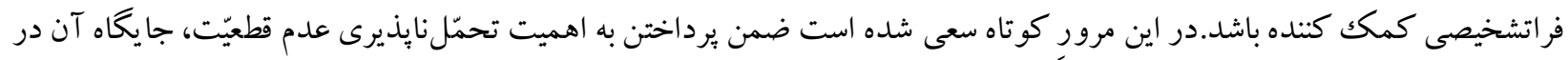
يديد آيى و تداوم اختلال هاى هيجانى بر رسى و تلويحاتى براى درمان اين سازه بر ایى متخصصين ارائه شود. كليد وازه: تحمّل نايذيرى عدم قطعيّت، اختلال هاى هيجانى، درمان اختلالهاى هيجانى، مرور كوتاه 
براى آسيبشناسى اختلالهاى روانى متعدد بخصوص

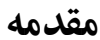
اختلالهاى هيجانى است (كارلتون، ويكس، هاول،

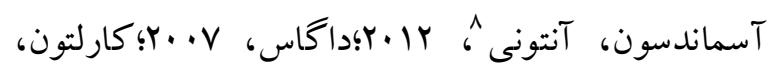

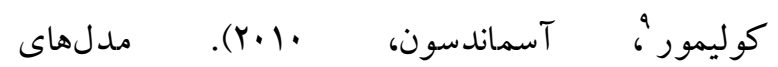
سايكوياتولوزى فرض مى كنند كه تحمّل نايذيرى عدم قطعيّت خصيصة مهم در تجربه مرتبط با اضطراب و و

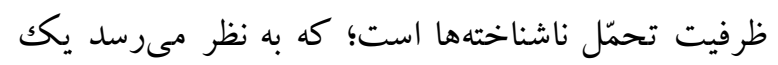
عامل آسيبيذير قوى مرتبط با گسترهاى از اختلالهاى

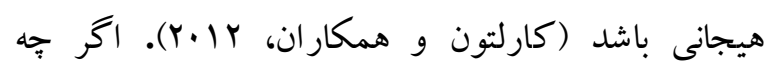
ويزگى تحمّلنايذيرى عدم قطعيّت ممكن است بين اختلالهاى هيجانى تظاهرات متفاوتى داشته باشد و به واسطة عوامل زمينهاى، متفاوت به نظر برسد، با اين حال نقش كليدى و مهمى در نگرانى، اضطراب حالت و و و آسيبشناسى مرتبط با اضطراب ايفا مى كند (باسول و

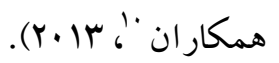
در اكثر مدلهاى درمانى به خصوص مدلهاى فراتشخيصى اختلالهاى هيجانى بر نقش عاملهاى

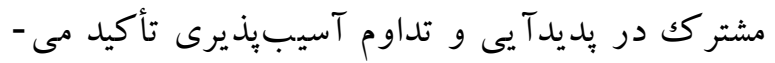

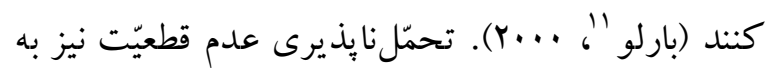
عنوان عامل آسيبٍٍير شناختى براى اختلال اضطراب

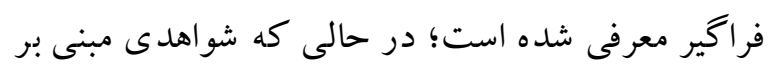
نقش تحمّل نايذ يرى عدم قطعيّت به عنو ان يكك عامل نكَه دارندهُ فراتشخيصى مهم در ساير اختلالهاى هيجانى نيز

$$
\text { وجود دارد (استارسويكك و برل با، 9. ㄷ). }
$$

با تو جّه به مفهوم سازى جند بُعدى اين سازه و همجنين نقش مؤلفههاى آن در اختلالهاى هيجانى، به نظر مى رسد كه بتوان تحمّل نايذيرى عدم قطعيّت را به عنوان

${ }^{8}$. Carleton, Weeks, Howell, Asmundson, Antony

9. Collimore

${ }^{10}$. Boswell, Hollands, Farchione, Barlow

11. Barlow

12. Starcevic, Berle

عدم قطعيّت ' مؤلفه اصلى در مدلهاى شناختى براى

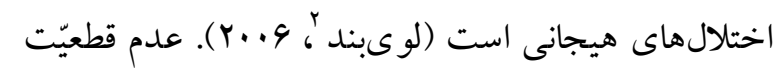
بيشبرآوردى از تهديد است كه به عنوان بخش هستهاى و اصلى در تظاهرات بالينى اضطراب شناخته مىشود. از

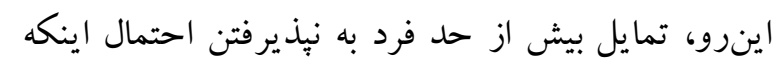

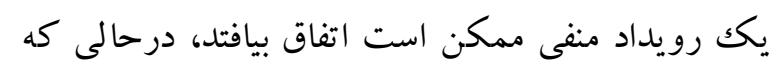
احتمال رخ دادن آن كم است را تحمّل نايذيرى عدم

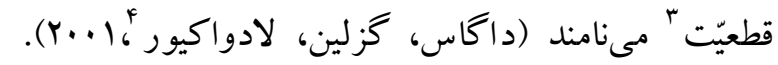

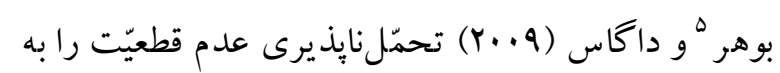
عنوان يك ويزگى سرشتى تعريف مى كنند كه نشان دهنده تمايل فرد به واكنش منفى در سطح هيجانى، شناختى و رفتارى در موقعيّت هاى مبهم است. تحقيقات انجام شده در مورد اثرات جانبى تحمّلنايذيرى عدم قطعيّت بالا، در درجهُ اول بر روى نخَّانى متمركز شدهاند. به طور كلّى تحقيقات انجام شده تحمّل نايذيرى عدم قطعيّت را به عنو ان مهم ترين عامل بيشبينى كننده

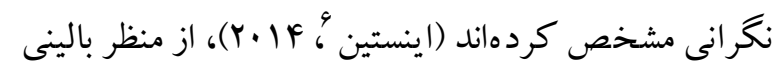

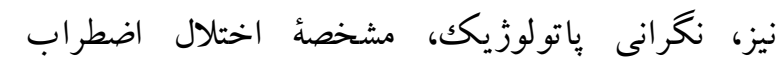

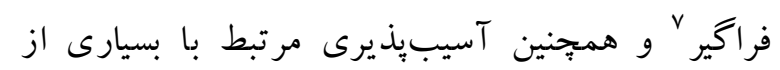
اختلالهاى اضطرابى و خلقى است. علاوه بر اين،

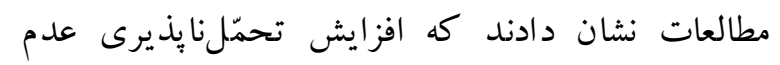

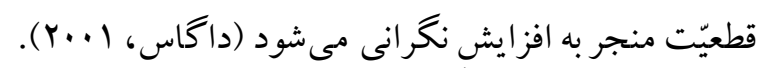
در همين راستا مطالعات متعددى از جمله كارلتون

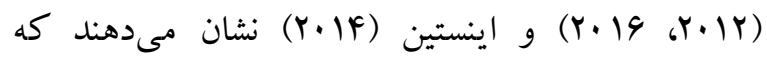
تحمّلنايذيرى عدم قطعيّت يكك عامل فراتشخيصى مهم

\footnotetext{
1 . Uncertainty

${ }^{2}$. Lovibond

3 . Intolerance of uncertainty

4. Dugas, Gosselin, Ladoucer

5. Buhr

${ }^{6}$. Einstein

${ }^{7}$. General anxiety disorder
} 
به عنوان مؤ لفههاى اصلى تحمّل نايذيرى عدم قطعيّت و

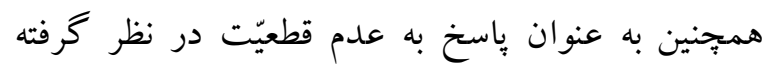
شدهاند كه به طور متفاوتى با نشانه باى اختلالهاى

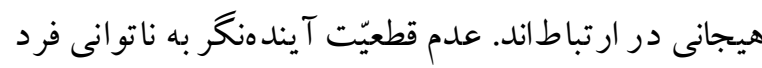
در بيشبينى مواجهه با رويدادهاى آينده منجر مىشود. در حالى كه بازدارنده بودن عدم قطعيّت به بازدارى رفتارى ناشى از عدم قطعيّت در مواجهه با رويدادهاى آينده اشاره دارند (كارلتون، نورتون و آسماندسون؛ V.... هر كدام از اين ابعاد به طور اختصاصى در اختلالهاى هيجانى مختلف نمود ييدا مى كنند. در اين راستا، كارلتون و همكاران (·r.|r) به اين نتيجه رسيدند كه اضطراب بازدارنده به طور اختصاصى با نشانهاى اضطراب

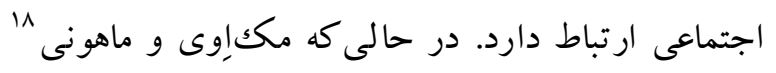

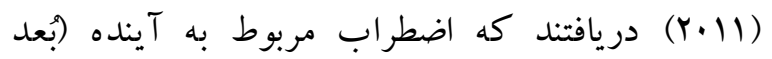
آيندهنگر) با نشانهاى اختلال اضطراب فراكير و اختلال

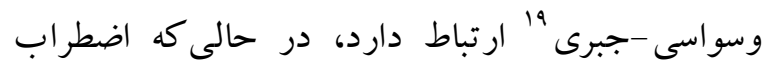
بازدارنده (بُعد بازدارنده) با نشانهاى فوبى اجتى اجتماعى،

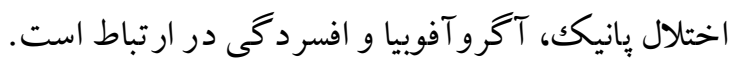

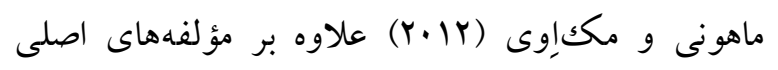
تحمّل نايذيرى عدم قطعيّت (به عنو ان مثال: تحمّل نا يذيرى

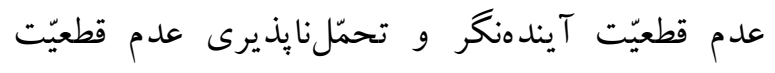
بازدارنده) نشان دادهاند كه تحمّل نا بذيرى عدم قطعيّت به ليه طور متفاوتى با علائم اختلالهاى هيجانى در ارتباط

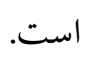
تحمّل نايذيرى عدم قطعيّتِ صفت شامل دو مؤلفه

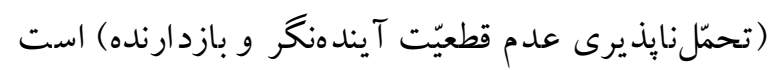

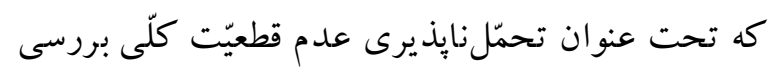
مىشود، در حالى كه، تحمّل نايذيرى عدم قطعيّتِ

18. McEvoy, Mahoney

${ }^{19}$. Obsessive-compulsive disorder
يكك آسيب: يذيرى مهم در سببشناسى، تداوم و درمان اختلالهاى هيجانى در نظر گرفت؛ بنابراين، مقاله حاضر در تلاش است ارتباط تحمّلنايذيرى عدم قطعيّت و اختلالهاى هيجانى را از حيث سبب شناسى و درمان آن مورد برر سى قرار دهد.

\section{تعريف تحمّل نايذيرى عدم قطعيّت}

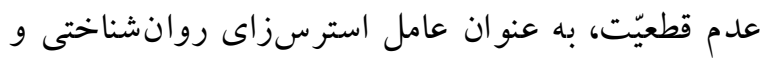
فيزيولوزيكى مهم نسبت به اينكه در آينده جه اتفاقى رخ خواهد داد تعريف شده است؛ كه با مشكلاتى از جمله مقابلة ناكارآمد، روانرنجورى، نياز به آيندهنگرى و وله واكنش هاى شناختى نسبت به ابهام همر اه است (كارلتون،

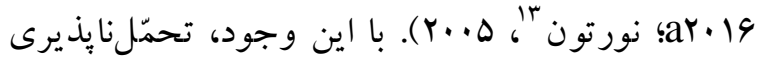
عدم قطعيّت، ناتوانى سرشتى فرد در تحمّل ِِاسخ آزاردهنده (كارلتون، 19 ·ar) و ترس ذاتى و ناساز گار انه

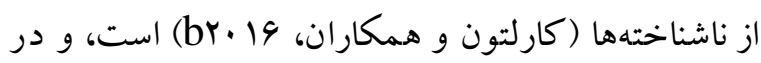
مواقعى كه احتمال رخ دادن يكك رويداد منفى غيرقابل قبول و تهديد كننده وجود داشته باشد (بوهر و داكاس،

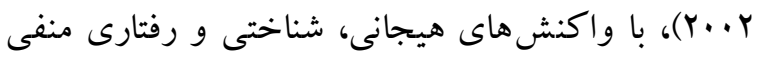

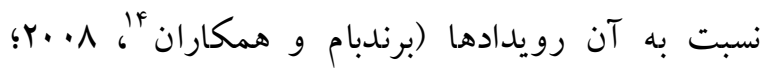

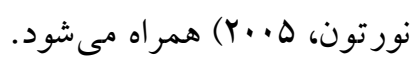

تحمّل نايذيرى عدم قطعيّت از دو بُعد تشكيل شده است:

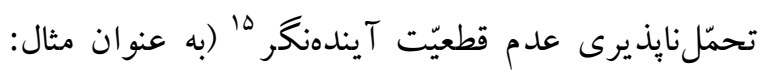
مى خو اهم بدانم كه در آينده براى من جه اتفاقى مى افتد) و تحمّل نايذيرى عدم قطعيّت بازدارنده با (به عنوان مثال: عدم قطعيّت من را از يا انداخته است) (كارلتون و و

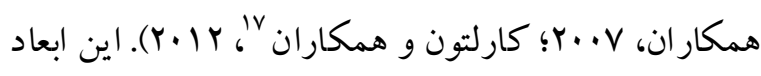

\footnotetext{
13. Norton

14 . Berenbaum, Bredemeier, Thompson

15. Prospective

16 . Inhibitory

17. Carleton, Mulvogue, Thibodeau, McCabe
} 
يس از برر سى ابعاد تحمّل نايذيرى عدم قطعيّت مى توان به

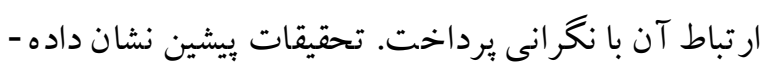

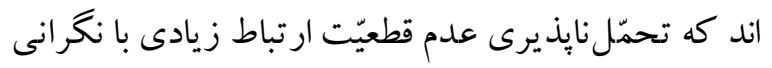
در جمعيّت بالينى و غير بالينى دارد. همجنين تحمّل -

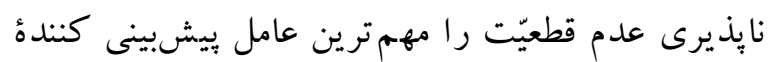

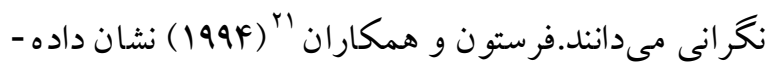
اند كه بين تحمّل نايذيرى عدم قطعيّت و نكرَ انى ارتباط

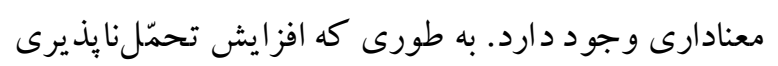
عدم قطعيّت منجر به افزايشِ نخر انى مى شود (لادوكيور،

$$
\text { كز لين، داكاس، .... (r). }
$$

به اين لحاظ تحمّل نايذيرى عدم قطعيّت به عنوان مؤلفه

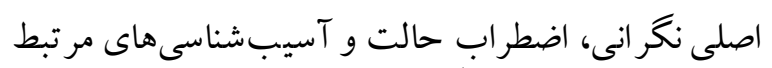
با اضطراب و اختلالهاى هيجانى شناخته شده است. از ديد كاه بالينى و آسيبشناسى نيز، نكر انى از مشخصههاى

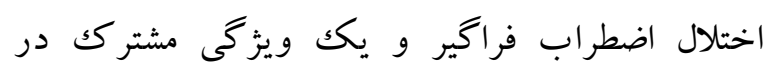
بسيارى از اختلالهاى اضطرابى و خلقى است و نيز با رويدادهايى كه با تحمّل نايذيرى عدم قطعيّت همراه است، مشخص مىشود. اين تعريف نقش اصلى عدم قطعيّت دربارهٔ رويدادهاى آينده را مشخص مى كند (داكاس، فرستون، لادو كيور، 199V). به طور كلّى، اين

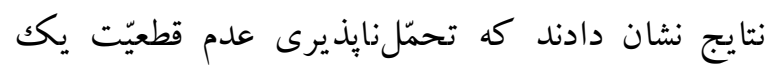
متغير كليدى براى فهم ما از نكر انى است.

\section{تحمّل نايذيرى عدم قطعيّت و اختلالهاى} هيجانى با وجود آنكه مؤلفهُ تحمّل نايذيرى عدم قطعيّت در ارتباط با اختلال اضطراب فراگير مطرح شدهاست (لاكسن،

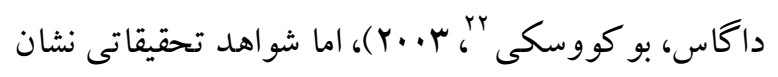

${ }^{21}$. Freeston, Rheaume, Letarte, Dugas, Ladouceur

${ }^{22}$. Laugesen, Dugas, Bukowski
موقعيّت -ويزَه به اين صورت است كه عدم قطعيّتِ افراد مرتبط با موقعيّى است كه در آن رخ داده است (به عنوان مثال؛ عدم قطعيّت دربارهٔ علل نشانههاى جسمى اضطراب براى اختلال بِانيكك و يا عدم قطعيّت مربوط به بيامد افكار

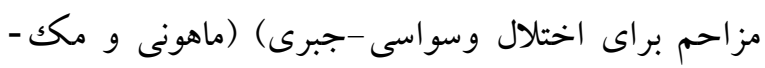

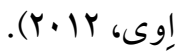
ماهونى و مككِاوى (Y.11) اخيراً دريافتند كه واكنش مبتلايان به اختلالهاى اضطر ابى متفاوت به عدمقطعيت، موقعيّت-ويزه است تا يكك واكنش عمومى و كلّى. همجِنين نشان دادند تحمّل نا ٍِذيرى عدم قطعيّتِ موقعيّت ويزه با نشانهاى اختلال اضطراب فراكير و اختلال اضطراب وسواسى -جبرى، فوبى اجتماعى، افسردكى، اختلال بانيك و آكرو افوبيا مرتبط است. نشانههايى وجود دارد كه تحمّل إيذيرى عدم قطعيّتِ صفت ممكن است ارتباط ضعيف ترى با اختلال بانيكك به نسب اختلالهاى

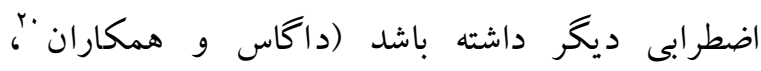
ه.(Y)، با وجود اين، مطالعات أخير نشان دادهاند كه

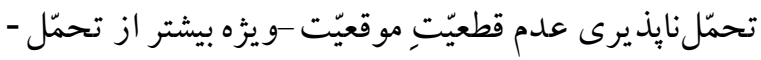
نايذيرى عدم قطعيّتِ صفت بيشبينى كنندة نشانهاى اختلال هِانيكك و آكروافوبيا است (ماهونى و مككاوِى،

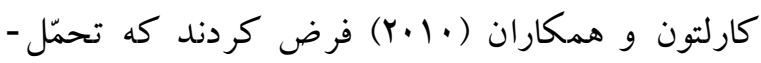
نايذيرى عدم قطعيّت به طور اختصاصى با موقعيّتهاى اجتماعى ارتباط دارد كه ممكن است عامل اصلى در لئل نشانه هاى معين فوبى اجتماعى باشد؛ به عنو ان مثال مطرح كردند كه عدم قطعيّت اغلب با افكار منفى تكرار شونده تجربه شده در قبل، حين و بعد از موقعيّتهاى اجتماعى مربوط مى شود.

${ }^{20}$. Dugas, Marchand, Ladouceur 
اضطراب جدايى بزر گسالان (بولن، ريجنتجز، كارلتون،

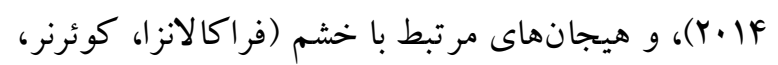

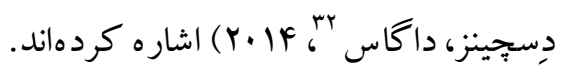

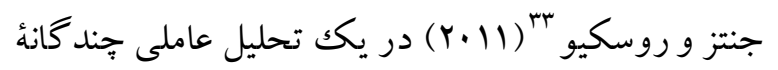

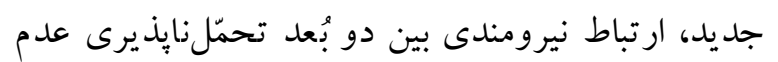

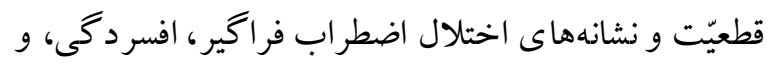
اختلال وسواسى -جبرى بيدا كردند. علاوه بر اين، مكك إوى و ماهونى (Y (Y) نشان دادند كه اجزاى مختلفى از تحمّل نايذيرى عدم قطعيّت ارتباط نسبتاً متوسطى با روان - مانى رنجورى و نشانهايى از اختلال اضطراب فراگير، اختلال

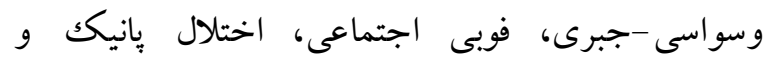

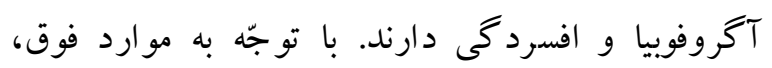
شواهد موجود از تحمّلنايذيرى عدم قطعيّت به عنوان يكك فرايند فراتشخيصى مرتبط با طيف كستردهاى از اختلال ها حمايت مى كنند. شواهد قابل توجّهى از مطالعات انجام شده در بين جمعيّت هاى بالينى و غير بالينى نشان مىدهند كه تحمّل نايذيرى عدم قطعيّت يكك عامل فراتشخيصى براى

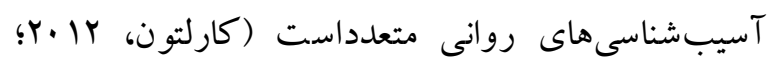

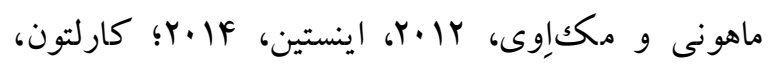

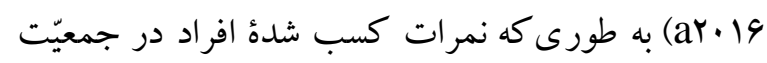
بالينى از جمعيّتهاى غير بالينى بالاتر است (داكاس و

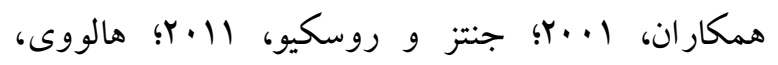

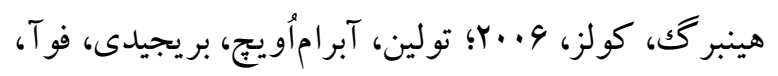

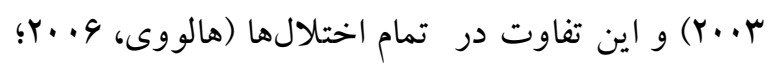

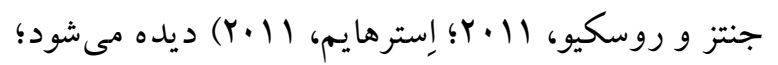
به علاوه، اين افزايش نمرات با همبودى هر اختلال با

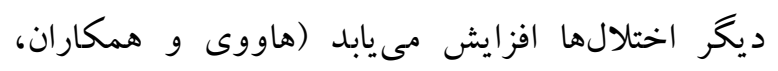

${ }_{33}^{32}$. Fracalanzam Koerner, Deschenes, Dugas

${ }^{33}$. Gentes, Russcio
مىدهند كه تحمّل نايذيرى عدم قطعيّت را مى توان به عنوان يكك آسيبِيذيرى زيربنايى براى ابتلا به تمامى اختلالهاى هيجانى در نظر خرفت.

از اين رو تحمّل نايذيرى عدم قطعيّت با طيفى از اختلال -

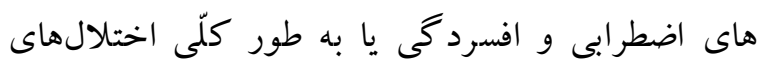
هيجانى در ارتباط است. مطالعات متعددى به نقش تحمّلانايذيرى عدم قطعيّت به عنوان علامت بيشبينى كنندهُ قابل توجّه در اختلالهاى اضطراب فراخير

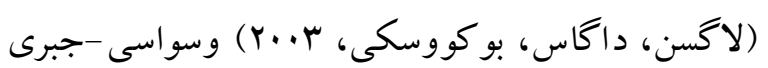
(استكتى، فراست، كوهن، 1991ا؛هولاوى، هيمبر گی،

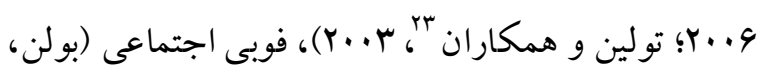

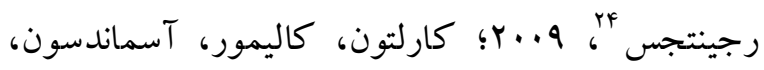

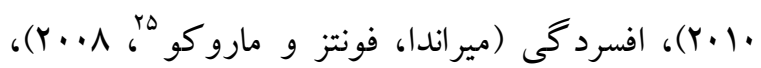

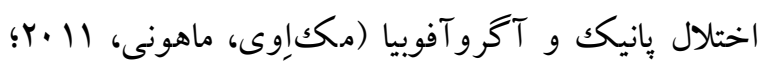

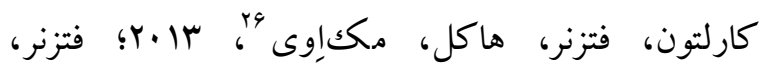

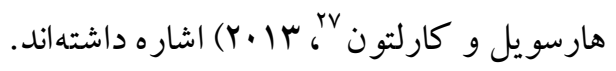
همجِنين تحقيقات أخير به نقش تحمّل نايذيرى عدم قطعيّت در علائم اختلالهاى اضطراب سلامتى (بولن،

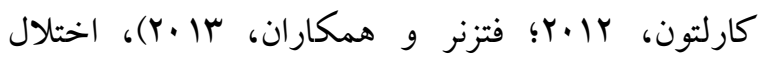
استرس بس از سانحه (فتزنر و همكاران، سا •Y) اختلال -

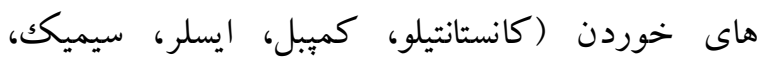

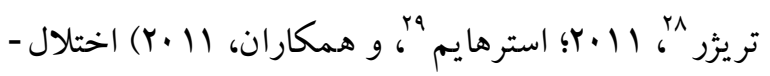
هاى طيف اوتيسم (بولتر، فرستون، سوث، رادجرز 'ب

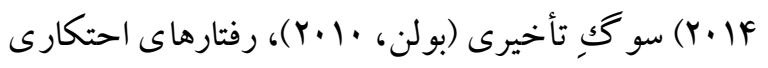

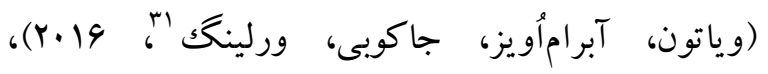

\footnotetext{
. Tolin, Abramowitz, Brigidi, Foa

24 . Boelen, Reijntjes

25. Miranda, Font es, Marroqun

26. Carleton, Fet zner, Hackl, McEvoy

27 . Fetzner, Horswill, Boelen, Carleton

28 . Konstantellou, Campbell, Eisler, Simic, Treasure

29. Sternheim, Startup, Schmidt

30. Boulter, Freeston, South, Rodgers

31. Wheaton, Abramowitz, Jacoby, Zwerling
} 
كردند. همجنين لادو كيور و همكاران (1999) دريافتند كه بيماران با يكك تشخيص اوّليه و يا ثانوّيه از اختلال

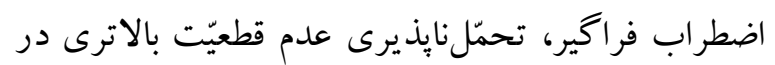

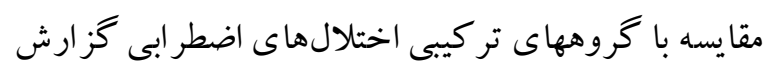

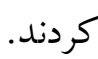

نه تنها تحمّل نايذيرى عدم قطعيّت با اختلالهاى جند كانه مرتبط است بلكه ابعاد تحمّل نايذيرى عدم قطعيّتِ صفتى و تحمّل نايذ يرى عدم قطعيّتِ موقعيّت -ويزّه نيز با افزايش

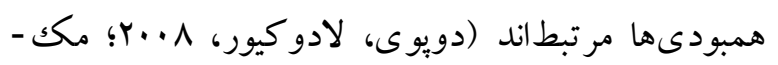

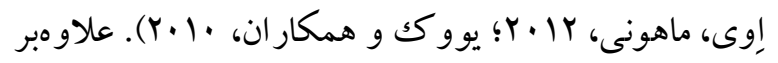

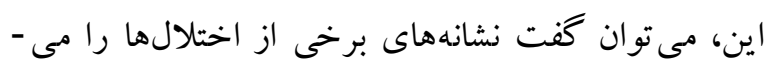
توان به عنوانى واكنشى با هدف كاهش و اجتناب از تحمّل نايذيرى عدم قطعيّت فرمولبندى كرد.

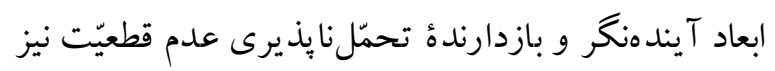
به طور متفاوتى با علائم اختلال هيجانى در ارتباطاند

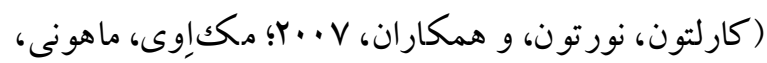

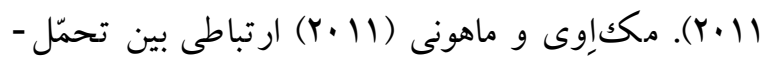
نايذيرى عدم قطعيّت آيندهنگ با علائم اختلال اضطراب فراگير و اختلال وسواسى -جبرى و تحمّلنايذيرى عدم عدم

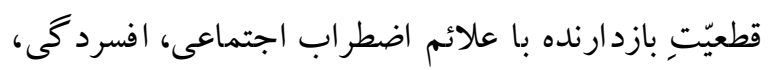
اختلال بانيكك، و آكروافوبيا در يكك نمونهُ بالينى يافتند. نتايج آنها با تحقيقات مربوط به ارتباط تحمّلنايذيرى عدم قطعيّتِ بازدارنده با اضطراب اجتماعى، افسردگى لَّى

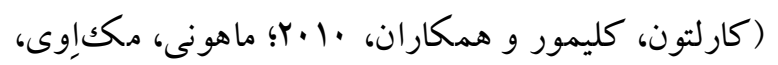

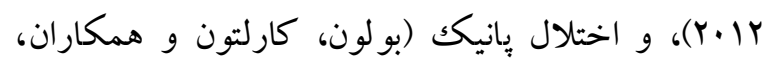

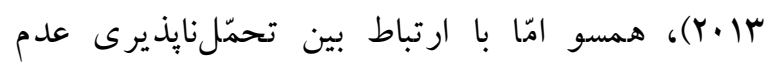
قطعيّت بازدارنده و اختلال اضطراب فراگير و اختلال

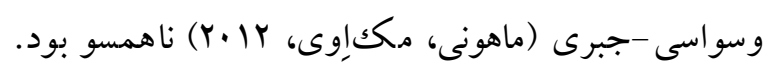
علاوه بر اين، تحمّل نايذيرى عدم قطعيّت بازدارنده بـ بـا

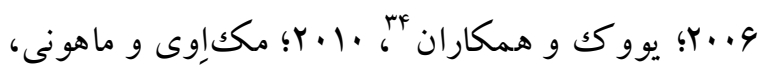

در راستاى افزايش تحمّل نايذيرى عدم قطعيّت متناسب با

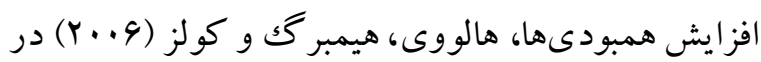
يكك نمونهُ مشابه دريافتند كه شركت كنند كان با تر كيبى از نشانههاى اختلال اضطراب فراخير و اختلال وسواسى جبرى، تحمّلنايذيرى عدم قطعيّت بالاترى نسبت به آن دسته از بيمارانى كه فقط نشانهاى جداكانه اختلال اضطراب فراگير يا اختلال وسواسى ججبرى داشتند، كزارش كردند. در مطالعه ديخر، كارلتون و همكاران

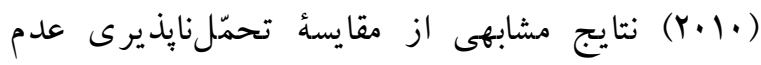
قطعيّت در افرادى با نشانهاى اضطراب فراخير و يا فوبى لهى اجتماعى گزارش كردند. به طور مشابهى بيماران داراى

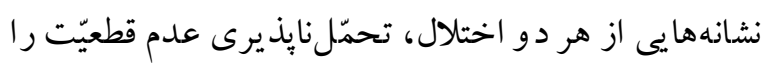
از افرادى كه نشانههايى از تنها يكك اختلال داشتند، بيشتر كزارش كردند. ميزان تحمّل نايذيرى عدم قطعيّت براى اين افراد با نشانهاى فوبى اجتماعى و اضطراب فراگير

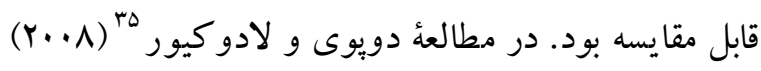
بيماران مبتلا به اختلال اضطراب فراخير همبود با اختلال افسردگى اساسى در مقايسه با بيماران مبتلا به اختلال

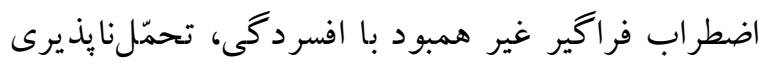

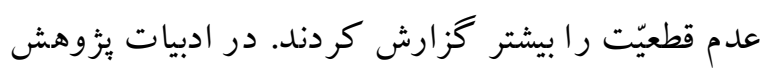
مطالعات معدودى وجود دارند كه با نتايج بالا همخوانى

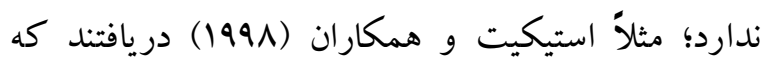
شر كت كنند كان مبتلا به اختلال وسواسى -جبرى، تحمّل نايذيرى عدم قطعيّت بيشترى را در مقايسه با گروههاى تركيبى اختلالهاى اضطرابى (شامل؛ اختلال پِانيك؛،

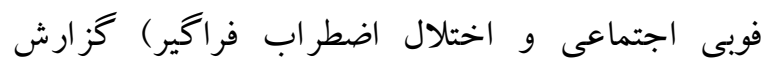

\footnotetext{
${ }^{34}$. Yook, Kim, Suh, Lee

35 . Dupuy, Ladouceure
} 
منفى نسب به مشكل و اجتناب شناختى در افراد مبتلا به

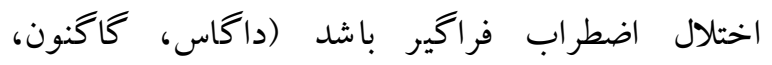
لادوكيور و فرستون؛ 1991). داخاس و لادوكيور (..... به اين نتيجه رسيدند كه در طول فرايند درمان، تغييرات در تحمّلنايذيرى عدم قطعيّت مقدم بر تغييرات در

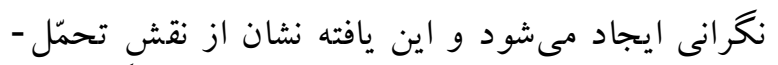

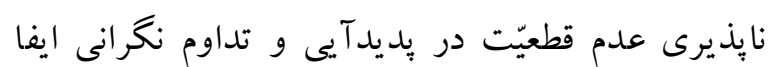
مى كند (لاجسن، داكاس، بو كووسكى، r...r). علاوه بر اين مطابق با مدل داكاس، مطالعات متعددى

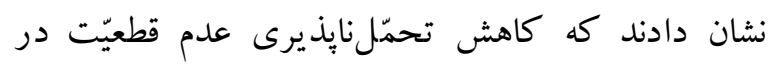
اختلال اضطراب فراگير منجر به كاهش نغرانى و و برعكس افزايش آن باعث بالا رفتن شدّت علائم اختلال

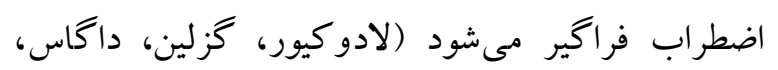
F... كلى در طول دورهُ درمان شناختى كرفتارى براى اختلال اضطراب فراكير، كاهش در تحمّل نايذيرى عدم قطعيّت بيشتر از كاهش در نخرانى اتفاق افتاده است (داكاس،

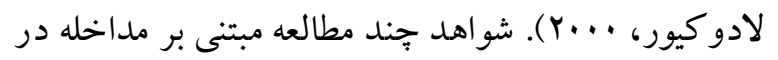
تحمّل نايذيرى عدم قطعيّت و تغييرات برسى شده در تحمّل نايذيرى عدم قطعيّت طى رواندرمانى (لادو كيور، .

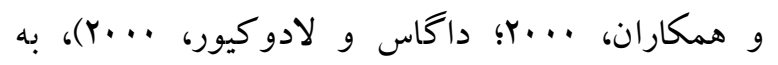
كاهش قابل توجّه تحمّلنايذيرى عدم قطعيّت در درمان شناختى كرفتارى براى اختلال اضطر اب فراخير دست بيدا كردهاند. علاوه بر اين، يُزوهش در جمعيّت بالينى نشان

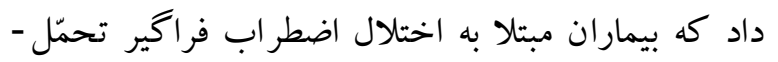
نايذيرى عدم قطعيّت بيشترى نسبت به بيماران مبتلا به ديخر اختلالهاى اضطرابى از خود نشان مىدهند

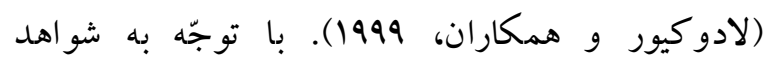
مطالعات انجام شده در زمينهُ تحمّل نايذيرى عدم قطعيّت
اختلال استرس يّ از آسيب (فتزنر و همكاران، سا•r) ارتباط داشته است.

تحمّل نايذيرى عدم قطعيّت و درمان اختلال هاى هيجانى با توجّه به نتايج فوق و نقش بارز تحمّل نايذيرى عدم

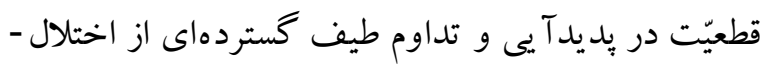
هاى هيجانى، اكنون به نقش تحمّل نايذيرى عدم قطعيّت در درمان اختلالهاى هيجانى مى يردازيم. در ابتدا درمانهاى تحمّل نايذيرى عدم قطعيّت ويزّه در مدلهاى درمان شناختى كرفتارى مانند مدل داكًاس وجود داشتهاند. تمركز اصلمى مدل داگاس بر علل شكل گيرى و و فرآيند تداوم نكرانى و همجينين ناتوانى در تحمّل عدم قطعيّت در ايجاد علائم و نشانهاى اختلال اضطراب فراگير است. در مدل داگاس، موقعيّتهاى اضطراب انخيز باعث مىشوند فرد درگير سؤالات بىيايان "جهـ مىشود اكر..." شود. به دليل اينكه فرد مبتلا به اختلال اضطر اب فر اگير نمى تواند عدم قطعيّت را تحمّل كند و از طرف ديخر، به نخرانى و بيامدهاى مثبت آن باور دارد، اين سؤالات معمولاً بدون جو اب مى مانند، و فرد را دهِار نخرانى مى كنند. اين نكرانى همراه با احساس اضطراب، منجر به جهت گيرى منفى نسبت به مشكل و اجتنابهاى شناختى مى گردد. از طرفى جهت گيرى منفى نسبت به به

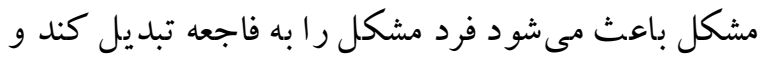
به تو انايىهاى خود براى حل مشكل اعتقاد نداشته باشد؛

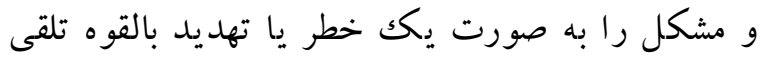
كند. ممكن است فرد هنگام مو اجهه با مشكل سر يعاً ناميد

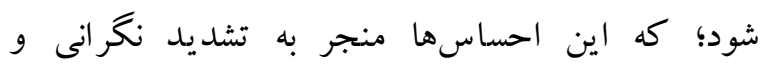

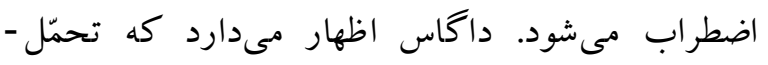
نايذيرى عدم قطعيّت مى تواند بيشزمينهُ جهت گيرى 
است؛ اين مدل فرض مى كند اختلالهاى خاص ممكن است تظاهرات متفاوتى از مكانيسمهاى زيربنايى باشند.

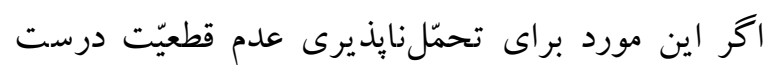

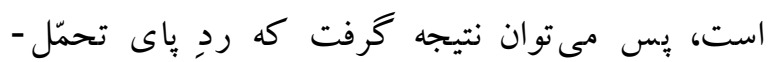

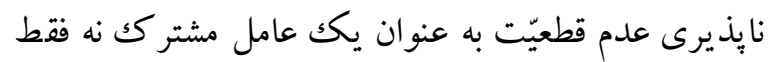
در اختلال اضطراب فراخير و اختلال وسواسى-جبرى بلكه در ساير اختلالهاى هيجانى به همان خوبى قابل رديابى است. أخير اً مطالعه ديخرى نيز در زمينهُ توسعهُ مدل فر اتشخيصى با تمركز بر تحمّل نايذيرى عدم قطعيّت توسط اينستين (Y.|F) قطعيّت به عنوان يكك عامل فراتشخيصى مهم در اكثر اختلالها بخصوص اختلالهاى هيجانى برداخته شده

مدل توسعه يافتهُ اينستين (Y|F) به متخصص بالينى

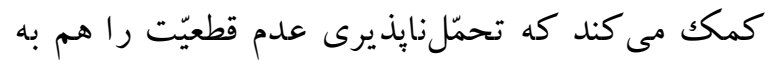

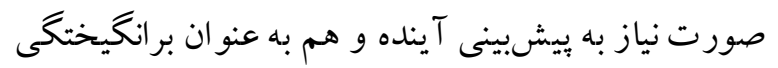
عدم قطعيّت مورد بررسى قرار دهد. عدم قطعيّت به عنوان

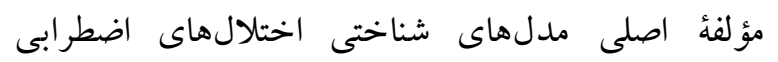
شناخته شده، كه به بيش برآوردى از تهلديد به عنوان

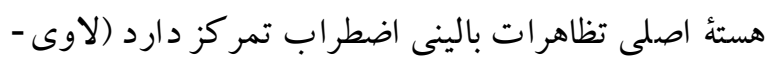

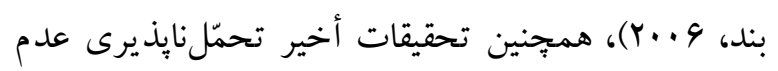

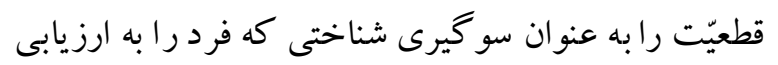
منفى موقعيّتهاى نامعلوم هدايت مى كند، مفهومسازى

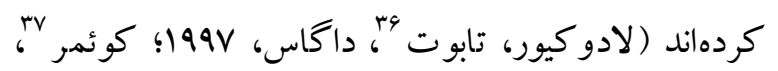

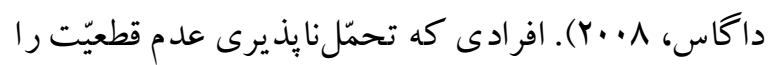
تجربه مى كنند احتمال دارند رويدادهاى منفى آينده را با توجّه به احتمال كم رِخ دادن واقعى حوادث، تهد يد آميز

36. Talbot

${ }^{37}$. Koerner
در مدل داكاس، مشخص شده است كه اين مدل تنها به فرمولبندى تحمّلنايذيرى عدم قطعيّت در اختلال اضطراب فراكير يرداخته است و آن را در مداخلات درمانى خاص اختلال اضطراب فراكير مورد توجّه قرار

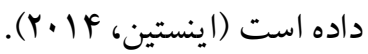
از طرف ديخر و همانطور كه در متن آمده است، تحمّل نايذيرى عدم قطعيّت يكك سازه فراتشخيصى است. مدل هاى فراتشخيصى اختلالهاى هيجانى به نقش عامل هاى مشتر كك در بيدايش و تداوم آسيب تأكيد مى كنند (بارلو،

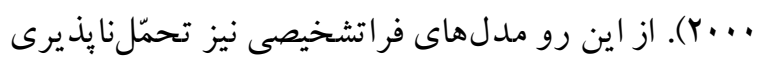
عدم قطعيّت را مشخصهُ فراتشخيصى در اختلالهاى هيجانى مختلف دانستهاند. تحمّل نايذيرى عدم قطعيّت نيز به عنوان يكك عامل آسيبِيذير شناختى براى اختلال

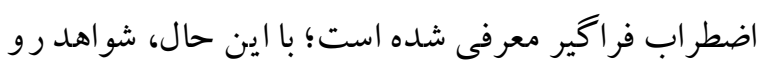
به رشدى وجود دارد كه نشان مىدهد تحمّل نايذ يرى عدم قطعيّت عامل تداوم بخش و نخهدارندهُ فراتشخيصى در اكثر اختلالهاى هيجانى است (استراسويك، برل،

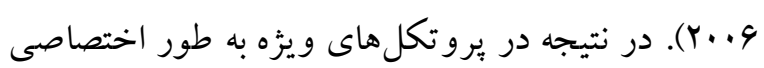
(مانند درمان فراتشخيصى) شواهدى براى كاهش تحمّل نايذيرى عدم قطعيّت به دست آمده است. باسول و و

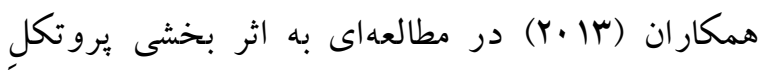
يكِيارجه در كاهش تحمّل نايذيرى عدم قطعيّت بِرداخته اند. محققان در اين بثزوهش به اين نتيجه رسيدند كه مشكل تحمّل نا بذ يرى عدم قطعيّت با تلاشهاى شناختى و رفتارى براى كاهش عدم قطعيّت و افزايش ادراك كنترل (هم تجارب وييامدهاى بيرونى و هم درونى) همراه است

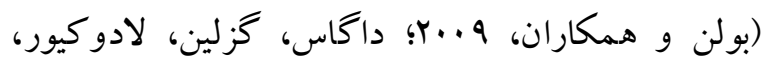

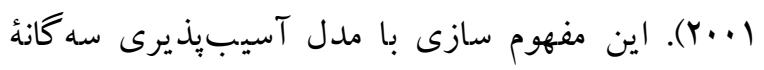

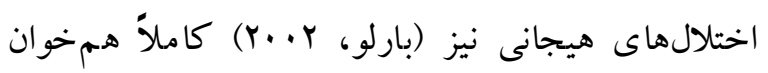


به طور كلّى رويكر دهاى فر اتشخيصى اختلالهاى هيجانى بر فرايندهاى زيربنايى كه ممكن است در تمام اختلالها مشترك باشد و به بديدآيى و تداوم آسيبذيذيرى منجر

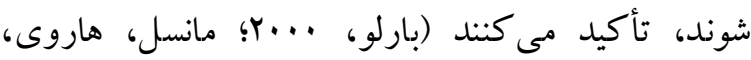

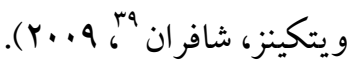

\section{نتيجه كيرى}

هدف اين مطالعه ارائه جارجوبى برى براى درك جايڤاه تحمّل نايذيرى عدم قطعيّت در آسيبشناسى اختلالهاى هيجانى و مدلهاى درمانى تشخيص -ويزه و فراتشخيصى جهت مداخله در آن است. همانطور كه در بالا اشاره كرديم تحمّلنايذيرى عدم قطعيّت يكك سازهُ فراتشخيصى در اختلالهاى هيجانى است. با اين وجود ارزيابى آن به عنوان يكك عامل مداخله كننده در درمان بروتكلهاى غير اختصاصى مهم است. با مرور مطالعات بيشين، درصور تى كه بيذيريم تحمّل نايذيرى عدم قطعيّت مؤلفه اختصاصى براى اختلال

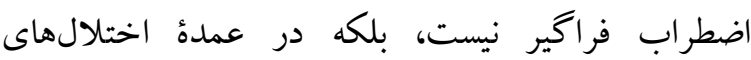
هيجانى مانند اختلال وسواسى -جبرى، اختلال اضطراب

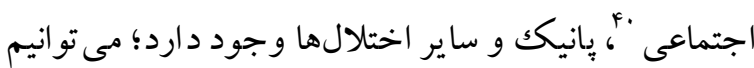

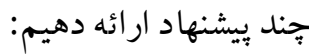
در ابتدا بيشنهاد مى كنيم با توجّه به شو اهدى كه براى اين

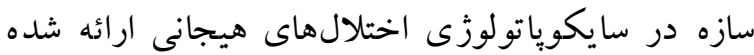

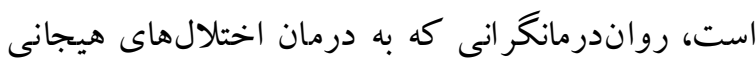
مى يردازند، در يروسهٔ درمانى (يا در يرو تكلهاى خود ) تحمّل نايذيرى عدم قطعيّت را به عنوان يكك مودال جندجلسهاى كانون درمان قرار دهند، و يا اينكه بروتكل هاى درمانى را متناسب با ميزان بالا بودن تحمّل بإيذيرى
و غيرقابل قبول در نظر بخيرند (داكاس، گزلين،

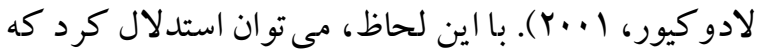
شناسايى عدم قطعيّت به عنوان يكك سازه، در طيفى از اختلالها با ويز گَى اضطر ابى وجود دارد.

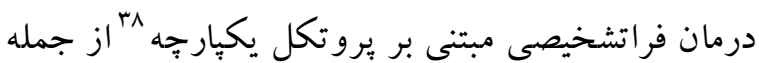
درمانهايى است كه در بِاسخ به ازدياد بروتكلهاى درمانى تكك تشخيصى توسعه يافت (بارلو، ا. (Y). دههها تحقيق، همبودى و هميوشى قابل توجّهى را در ميان اختلال هاى اضطر ابى و خلقى و تمايل در شناسايى عامل هاى زيربنايى و مرتبط براى كمكك در مفهومسازى و درمان توسعه يافته نشان مىدهند (ماهونى و مككاوِىى،

بروتكل يكِارجه براى درمان فراتشخيصى اختلالهاى هيجانى، درمان شناختى رفتارى هيجان محور است كه براى استفاده در اختلالهاى اضطرابى و خلقى تكك قطبى و همجِنين ساير حوزههاى مرتبط با مؤ لفهاى هيجانى شديد طراحى شده است. اين يروتكل متشكل از راهبردهاى شواهدمحور مبتنى بر درمان شناختى رفتارى براى مداخله در سازههاى مشتركى دخيل در آسيبشناسى اختلالهاى هيجانى است. هر جند در اين بروتكل به طور اختصاصى مودالى براى تحمّل نايذيرى عدم قطعيّت طراحى نشده است امّا مودالهاى شناسايى و جلو گيرى از الكوهاى اجتناب از هيجان و رفتارهاى

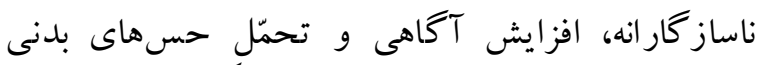
ناشى از هيجان و رويارويى با حس هاى بدنى و رويارويى هيجانى مبتنى بر موقعيت با كاهش تحمّل نايذيرى عدم

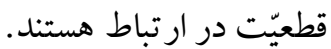

39. Mansell, Harvey, Watkins, Shafran

${ }^{40}$. Social anxiety disorder

${ }^{38}$. Unified Prot ocol 
تحمّل نايذيرى عدم قطعيّت مى تواند در حال حاضر يكك عامل مهمم در درمان باشد.

در نهايت با توجّه به مطالعات مطرح شده مى توان كفت، تحمّل نايذيرى عدم قطعيّت نقش قابل توجّهى در سبب شناسى و درمان اختلالهاى هيجانى دارد و درمانكران بايد به اين سازه و تظاهرات بالينى آن در كار با بيماران مبتلا به اختلالهاى هيجانى توجّه لازم راد داشته باشند.

\section{References}

Barlow, D. H. (2002). Anxiety and its disorders: The nature and treatment of anxiety and panic(2nd ed.). New York,NY: Guilford Press.

Berenbaum, H., Bredemeier, K., \& Thompson, R. J. (2008). Intolerance ofuncertainty: exploring its dimensionality and associations with need forcognitive closure, psychopathology, and personality. Joumal of Anxiety Disorders, 22, $117-125$.

Boelen, P. A. (2010). Intolerance of uncertainty and emotional distress following the death of aloved one. Anxiety, Stress \& Coping, 23, 471-478. doi:10.1080/10615800903494135

Boelen, P. A., \& Carleton, R. N. (2012). Intolerance of uncertainty, hypochondriacal concems,obsessive-compulsive symptoms, and worry. The Journal of Nervous and MentalDisease, 200, 208-213. doi:10.1097/NMD.0b013e318247cb17

Boekn, P. A., \& Reijntjes, A. (2009). Intolerance of uncertainty and social anxiety. Joumal ofAnxiety Disorders, 23,130135.doi:10.1016/j.janxdis.2008.04.007

Boelen, P. A., Reijntjes, A., \& Carleton, R. N. (2014). Intolerance of uncertainty and adultseparation anxiety. Cognitive Behaviour Therapy, 43, 133-144.doi:10.1080/16506073.2014.888755

Boswell, J. F., Thompson-Hollands, J. Farchione, T. J, Barlow, D. (2013). Intolerance of uncertainty: A common factor in the treatment of emotionaldisorders. J Clin Psychol, 1-16.
عدم قطعيّت در مراجعين خود تنظيم كنند، زير ابالا بودن تحمّل نايذيرى عدم قطعيّت در بيماران مى تواند اثر بخشى سي برو تكل هاى درمانى رابه جالش بكشد. براى مثال، يكك متخصص بالينى ممكن است در درمان اختلال اضطرابى از مواجهه سازى استفاده كند، امّا عدم لمّل قطعيّت را به عنوان يكك بخش مهمّ از منطق و هدف

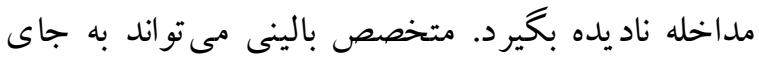
تأكيد زياد بر توانايى مقابله، انتظارات ناشى از نتايج

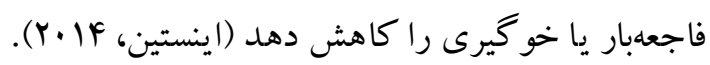
در وهلهُ دوم بيشنهاد مى كنيم در صورتى كه در اجراى يروتكلهاى درمانى تشخيص -ويزه از لحاظ نظرى اين امكان وجود نداشته باشد كه تحمّل نايذيرى عدم قطعيّت را مورد متوجه قرار داد؛ متخصص بالينى مىتواند از درمانهاى فراتشخيصى مانند پيروتكل يكيارجه براى درمان و يا كاهش تحمّل نايذيرى عدم قطعيّت استفاده كنיد. با اين وجود اكر تحمّلإيذيرى عدم قطعيّت يك مكانيسم مشترك در آسيبشناسى اختلالهاى هيجانى باشد، يس تغيير در اين عامل در اثر درمان بايد با نتايج مثبت تغيير در طيفى از اختلالها همراه باشد. بنابراين بحث تغيير يكك عامل مشتر كك كلى مطرح است. از اين منظر در مطالعهُ حاضر تلاش شد تا با ارائُٔ شو اهد نظرى و عملى، نقش ابعاد مختلف اين سازه در بديدآيى و درمان اختلالهاى هيجانى مورد بررسى قرار گيرد. از آنجا كه آشفتكى حاصل از تجربيات عدم قطعيّت با سطوحى از علائم در اختلالهاى هيجانى مختلف همراه است و از آنجايى كه راهبردهاى كه براى اجتناب از عدم قطعيّت و افزايش ادراكى كنترل به كار مىروند به دقّت با بـا عامل هاى نگهدارنده آسيبشناسى روانى گره خوردهاند، 
Boulter, C., Freeston, M., South, M., \& Rodgers, J. (2014). Intolerance of uncertainty as aframework for understanding anxiety in children and adolescents with autism spectrumdisorders. Journal of Autism and Developmental Disorders, 44, 13911402doi:10.1007/s10803-013-2001-x

Buhr, K., \& Dugas, M. J. (2009). The role of fear of anxiety and intolerance of uncertainty in worry: Anexperimental manipulation Behaviour Research and Therapy, 47, 215223.

Carleton, R. N. (2016a). Fear of the unknown: One fear to rule them all? J.Journal of Anxiety Disorders, 41, 5-21. doi:10.1016/j.janxdis.2016.02.007

Carleton, R. N. (2016b). Into the unknown: A review and synthesis of contemporary models involving uncertainty. Joumal of Anxiety Disorders, 39, 30-43.

Carleton, R. N., Collimore, K. C., \& Asmundson, G. J. G. (2010). 'It's not just the judgements - it's that I don't know": Intolerance of uncertainty as a predictor of social anxiety. Journal of Anxiety Disorders, 24, 189-195.

Carleton, R. N., Fetzmer, M. G., Hackl, J. L., \& McEvoy, P. (2013). Intolerance of uncertainty asa contributor to fear and avoidance symptoms of panic attacks. Cognitive BehaviourTherapy, $\quad 42, \quad 328$ 341.doi:10.1080/16506073.2013.792100

Carleton, R. N., Mulvogue, M. K., Thibodeau, M. A., McCabe, R. E., Antony, M. M., and Asmundson, G. J. G. (2012a). Increasingly certain about uncertainty: intolerance of uncertainty across anxiety and depression. J. Anxiety Disord. 26, 468-479. doi:10.1016/j.janxdis.2012.01.011

Carleton, R. N., Norton, M. A., \& Asmundson, G. J. (2007). Fearing the unknown: ashort version of the intolerance of uncertainty scale. Joumal of AnxietyDisorders, 21, 105-117.

Carleton, R. N., Weeks. J. W., Howell A. N., Asmundson. G. J.G., Antony. M. M., McCabe. R. E. (2012b). Assessing the latent structure of the intolerance of uncertainty construct: An initial taxometric analysis. Joumal of Anxiety Disorders, 26, 150-157.

Dugas, M. J.(2007). Can the components of a cognitive model predict the severity of generalized anxiety disorder? Behav Ther., 38, 169178.doi:10.1016/j.beth.2006.07.002.

Dugas, M. J., Freeston, M. H., \& Ladouceur, R. (1997). Intolerance of uncertainty andproblem orientation in worry. Cognitive Therapy and Research, 21, 593-606Dupuy, J. -B., \& Ladouceur, R. (2008). Cognitive processes of generalised anxiety disorder in comorbid generalised anxiety disorder and major depressive disorder. Journal of Anxiety Disorders, 22,505-514.

Dugas, M. J., Gosselin, P., \& Ladouceur, R. (2001). Intolerance of uncertainty and worry: Investigating specificity in a nonclinical sample. Cognitive Therapy and Research 25, 551-558.

Dugas, M. J., Marchand, A., \& Ladouceur, R. (2005). Further validation of a cognitive-behavioral model of generalized anxiety disorder. Diagnostic and symptom specificity. Joumal of Anxiety Disorders, 19, 329-343.

Einstein, D. A. (2014). Extension of the transdiagnostic model to focus on intolerance of uncertainty: a review of the literature and implications for treatment. Clin. Psychol Sci. Pract.,21, 280300. doi:10.1111/cpsp.12077

Fetmer, M., Hoiswill, S., Boekn, P, \& Carleton, R. (2013). Intolerance of uncertainty and PTSDsymptoms: Exploring the construct relationship in a community sample with aheterogeneous trauma history. Cognitive Therapy and Research, 37, 725734.doi:10.1007/s10608-013-9531-6

Fracalanza, K., Koerner, N., Deschênes, S. S., \& Dugas, M. J. (2014). Intolerance of uncertaintymediates the relation between generalized anxiety disorder symptoms and anger.Cognitive Behaviour Therapy, 43, 122 132. doi:10.1080/16506073.2014.888754

Freeston, M. H., Rhéaume, J., Letarte, H., Dugas, M. J., \& Ladouceur, R. (1994). Whydo people 
worry? Personality and IndividualDifferences, 17,791-802.

Gentes, E. L. \& Ruscio, A. M. (2011). A meta-analysis of the relation of intolerance ofuncertainty to symptoms of generalized anxiety disorder, major depressive disorder, andobsessivecompulsive disorder. Clinical Psychology Review, 31, 923933.doi:10.1016/j.cpr.2011.05.001

Holaway, R. M., Heimberg, R. G., and Coles, M. E. (2006). A comparison of intolerance of uncertainty in analogue obsessive-compulsive disorder and generalized anxiety disorder. $\mathrm{J}$. Anxiety Disord. 20, 158-174. doi:10.1016/j. janxdis.2005.01.002

Koemer, N., \& Dugas, M. J.(2008). An investigation of appraisals in individuals vulnerable toexcessive worry: the role of intolerance of uncertainty. Cognitive Therapy and Research, 32,619-638.

Konstantellou, A., Campbell, M., Eisler, I., Simic, M., \& Treasure, J. (2011). Testing a cognitivemodel of generalized anxiety disorder in the eating disorders. Joumal of AnxietyDisorders, $\quad 25, \quad 864869$. doi:10.1016/j.janxdis.2011.04.005

Ladouceur, R., Dugas, M. J., Freeston, M. H., Rheaume, J., Bhis, F., Boisvert, J., . . . Thibodeau, N. (1999). Specificity of generalized anxiety disorder symptoms and processes. Behavior Therapy, 30, 191-207.

Ladouceur, R., Gosselin, P., \& Dugas, M. J. (2000). Experimental manipulation of intolerance ofuncertainty: A study of a theoretical model of worry. Behaviour Research and Therapy,38(9), 933-941. doi:10.1016/S00057967(99)00133-3.

Ladouceur, R., Talbot, F., \& Dugas, M. J. (1997). Behavioral expressions of intolerance of uncertainty in worry: Experimental findings. Behavior Modification, 21, 355-371. doi:10.1177/01454455970213006

Laugesen, N., Dugas, M. J., \& Bukowski, W. M. (2003). Understanding adolescent worry: Theapplication of a cognitive model Joumal of AbnormalChild Psychology, 31, 55-64.
Lovibond, P. F. (2006). Fear and avoidance: An integrated expectancy model In: Craske, M.G., Hermans, D., Vansteenwegen, D., (Eds). Fear and leaming: Basic science toclinical application. Washington, DC: American Psychological Association, pp. 117-132.

Mahoney, A. E. J., \& McEvoy, P. M. (2012). A transdiagnostic examination of intolerance ofuncertainty across anxiety and depressive disorders. Cognitive Behaviour Therapy, 41, 212-222.

Mansell, W., Harvey, A., Watkins, E, \& Shafran, R. (2009). Conceptual foundations of the transdiagnostic approach to CBT. Journal of Cognitive Psychotherapy, 23, 6-19. doi:10.1891/0889-8391.23.1.6

McEvoy, P. M., \& Mahoney, A. E. (2011). Achieving certainty about the structure of intoleranceof uncertainty in a treatment-seeking sample with anxiety and depression. Joumal ofAnxiety Disorders, 25, 112-122. doi:10.1016/j.janxdis.2010.08.010

Miranda, R., Fontes, M., \& Marroquín, B. (2008). Cognitive content-specificity in futureexpectnaices: role of hopelessness and intolerance of uncertainty in depression and GADsymptoms. Behaviour Research and Therapy, 46, 1151-1159.

Norton, P. J. (2005). A psychometric analysis of the intolerance of uncertainty Scaleamong four racial groups. Journal of Anxiety Disorders, 19,699-707.

Robichaud, M., \& Dugas, M. J. (2006). A cognitive behavioral treatment targeting intolerance for uncertainty. In G. Davey \& A. Wells (Eds.), Worry and its psychological disorders (pp. 289-304). Chichester, UK: Wiley.

Starcevic, V., \& Berle, D. (2006). Cognitive specificity of anxiety disorders: A review of selectedkey constructs. Depression and Anxiety, 23, 51-61. doi:10.1002/da20145

Steketee G, Frost RO, Cohen I. Beliefs in obsessivecompulsive disorder. Journal of AnxietyDisorders. 1998; 12525-537. [PubMed:9879033] 
Sternheim, L., Startup, H., \& Schmidt, U. (2011). An experimental exploration of behavioral andcognitive-emotional aspects of intolerance of uncertainty in eating disorder patients.Journal of Anxiety Disorders, 25, 806812. doi:10.1016/j.janxdis.2011.03.020

Tolin D. F., Abramowitz, J. S, Brigidi, B. D., \& Foa, E. B. (2003). Intolerance of uncertainty inobsessive-compulsive disorder. Journal of AnxietyDisorders, $\quad 17, \quad 233$ 242.doi:10.1016/S0887-6185(02)00182-2
Wheaton, M. G., Abramowitz, J. S., Jacoby, R. J., Zwerling J., \& Rodriguez, C. I. (2016). Aninvestigation of the role of intolerance of uncertainty in hoarding symptoms. Joumal ofAffective Disorders, 193, 208-214. doi:10.1016/j.jad.2015.12.047

Yook, K., Kim, K. H., Suh, S. Y, and Lee, K. S. (2010). Intolerance of uncertainty,worry, and rumination in major depressive disorder and generalized anxietydisorder. J. Anxiety Disord. 24,623-628.Doi.

10.1016/j.janxdis.2010.04.003. 